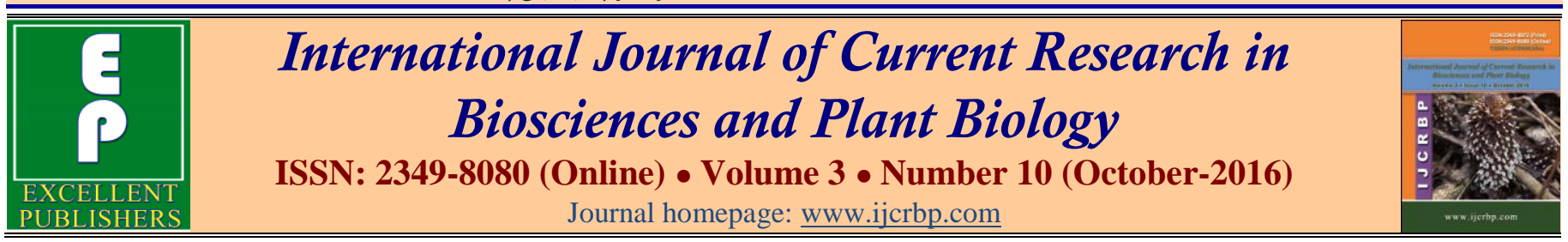

Review Article

doi: http://dx.doi.org/10.20546/ijcrbp.2016.310.010

\title{
Oxidative Stress, Reactive Oxygen Species (ROS) and Antioxidative Defense System, with Special Reference to Fish
}

\begin{abstract}
Asima Tripathy*
Assistant Professor in Zoology, Bhadrak Autonomous College (Department of Higher Education, Govt. of Odisha), Bhadrak- 756 10o, Odisha, India

*Corresponding author.
\end{abstract}

\begin{abstract}
A bstract
The concentration of oxygen in atmosphere is about $10 \%$, whereas in aquatic environment it is about $0.3 \%$. Since the availability of oxygen to aquatic animals is about 33 fold less than that of terrestrial organisms, oxygen concentration in the aquatic system is an important factor for regulation of fish health and reproduction. This paper reviews the knowledge of oxidative stress, ROS and Anti-oxidative defense system in various organisms and present status of information concerning oxidative stress in fish and attempts to resolve the reproductive consequences associated with oxidative stresses in fish under normal as well as different experimental states. Especially in fish there is a high risk of quality loss due to oxidation. Relatively few studies on the various antioxidants in fish are currently available. Studies on the interaction between the various endogenous antioxidants in fish are also very few. The relative concentration of antioxidants varies with the fish species as well as the type of fish muscle tissue. The quantity of these antioxidants may also fluctuate with storage time and handling post mortem. Control of lipid oxidation in fish involves utilizing processing and storage techniques that do not greatly decrease the activity of endogenous antioxidants.
\end{abstract}

\section{Article Info}

Accepted: 13 September 2016

Available Online: 06 October 2016

\section{Keywords}

Anti-oxidative defense system

Fish

Natural defense system

Oxidative stress

Reactive oxygen species (ROS)

\section{Introduction}

The concentration of oxygen in air is about $10 \%$ whereas in water it is about $0.3 \%$. Therefore, the availability of oxygen to aquatic animals is about 33 fold less than that of terrestrial organisms. However, several internal and external factors such as temperature, salinity, rate of photosynthesis by aquatic plants etc are known to influence oxygen concentration of aquatic environment. In aerobes oxygen is essential for the maintenance of vital functions of the cells. During respiration $80-95 \%$ of the total oxygen consumed by the body is reduced to water by electron transport chain of mitochondria.
However, 3-5\% of oxygen consumed by mitochondria is leaked. This leakage of oxygen from electron transport chain leads to formation of superoxide $\left(\mathrm{O}_{2}-\right)$ radical by reduction of an electron from the ground state of oxygen molecule (Turrens et al., 1985). However, during various metabolic activities the other sites of oxygen radical production are microsomes (Stat, 1988), peroxisomes (Dhaunsi et al., 1992) and cytosol (Shaw and Jayatilleke, 1990), which was latter extended by McCord and Fridovich (1969) into "superoxide theory of oxygen toxicity" reveals that superoxide formation is one of the major factors in oxygen toxicity. Addition of one or more electrons to $\mathrm{O}_{2-}$ forms peroxide ion $\left(\mathrm{O}_{2}{ }^{-2}\right)$. Fenton 
(1894) had found that when hydrogen peroxide $\left(\mathrm{H}_{2} \mathrm{O}_{2}\right)$ reacts with iron it forms hydroxyl radical $(\mathrm{HO})^{\text {- }}$. Hydroxyl radical is one of the potent oxidants, which affect every type of organic cellular macromolecules instantaneously, and results in lipid peroxidation (LPx), protein degradation enzyme inactivation, DNA damage and ultimately cell death. However, the partial reduction of oxygen forms reactive chemical intermediates. These intermediates are known as reactive oxygen species (ROS) or free radicals.

\section{Reactive oxygen species/ Free radicals}

The free radical can be defined as a chemical species, an atom or molecule that has one or more unpaired electrons in valance shell and is capable of existing independently. As free radicals contain an odd number of electron, which make it unstable, short lived and highly reactive; therefore it can react quickly with other compound, trying to capture the needed electron to gain stability. Generally, free radical attacks the nearest stable molecule, "stealing" its electron. When the attacked molecule loses its electron, it becomes a free radical itself, beginning a chain reaction cascade resulting in disruption of a living cell. The most important free radicals in biological system are radical derivatives of oxygen. Oxygen is required to transfer various substances for the release of the energy and detoxify xenobiotics. During this process oxygen acts as terminal electron acceptor and is eventually converted to more stable compound, water. This reduction of one molecule of $\mathrm{O}$ via the cytochrome oxidase system of respiratory chain requires 4 electrons. Such type of reduction is known as transvalent reduction of oxygen to water (Tandon et al., 2005). Sources of ROS in biological system are due to cellular metabolism such as mitochondrial electron transport, endoplasmic reticulum oxidation, Enzymatic activity etc and environmental factors such as drugs, pesticides, tobacco smoke, alcohol, radiations, high temperature, etc. However, these ROS are having both useful and harmful role.

\section{Useful roles of ROS}

ROS play an important role in many physiological processes. They are: regulation of gene transcription in higher eukaryotes (Meyer et al., 1994), development and differentiation (Allen, 1991), steroid hormone synthesis (Pradeep et al., 1990), mitochondrial oxidation (Sinclair et al., 1991), oxygen transportation by haemoglobin (Sinclair et al., 1991), cytochrome P 450 activity (Sinclair et al., 1991).

\section{Harmful roles of ROS}

It causes oxidation and peroxidation of proteins, lipids, and DNA, which can lead to significant cellular damage and even tissue or organ failure (ROS-mediated diseases). Knight (1995) in his review has related various diseases/ disorders to ROS (aging, atherosclerosis, brain disorders, cancer, cardiac myopathy, chronic granulomatous disease, diabetes mellitus, eye disorders, inflammatory disorders, iron overload, lung disorders, nutritional deficiency, radiation injury, rheumatoid arthritis, skin disorders, etc.)

\section{Oxidative stress}

Oxidative stress has been defined as a disturbance in the balance between the production of reactive oxygen species (ROS), or free radicals and antioxidant defenses, which may lead to tissue injury. Also, free radical can be defined as any chemical species that contains unpaired electrons in their outer orbit and thus can react virtually with all call components. Although, reactive oxygen species are crucial to normal biological processes, they are potentially dangerous and are commonly referred to as prooxidants. The reactive oxygen inermediates (including super oxide and hydroxyl radicals as well as hydrogen peroxide) can cause direct cellular injury by including lipid and protein peroxidation and damage to nucleic acid. Common examples of the free radicals include the hydroxyl radical $(\mathrm{OH})$, super oxide anion $\left(\mathrm{O}_{2}\right)$, transition metals such as iron and copper, nitric oxide (NO) and peroxynitrite $\left(\mathrm{ONOO}^{-}\right)$. Moreover, Betteridge (2000) reported that, the free radicals can be produced by several different biochemical processes within the body including: 1) The reduction of molecular oxygen to superoxide; 2) Byproducts of chemical reactions such as oxidation of catecholamine and activation of the arachidonic acid cascade product electrons, which can reduce molecular oxygen to super oxide; 3) production of superoxide and hypochlorous acid (HOC1), a powerful oxidant, by activated phagocytes;4)Nitric oxide production by vascular endothelium and other cells.

In addition, Shivakumar et al. (1982) recorded that, the levels of thiobarbituric acid reactive products, indicative of lipid peroxidation, were very low at birth and increased to adult levels by the $16^{\text {th }}$ day after birth. Moreover, the free radicals and lipid peroxidation have been reported to be increased in the aged brain of rats. Also, the lipid peroxidation showed an elevated increase with the aging: this fact is more evident in neuronal than 
in glial cells of rats. The increased levels of thiobarbituric acid-reactive substances (TBARS) suggest a net increase in the levels of oxygen free radicals which could be due to their increased production and /or decreased destruction.

\section{Influence of oxidative stress on health and brain ageing}

Oxidative stress arises because the antioxidant defense system of the human body is not entirely efficient. Under these conditions increased free radical production is likely lead to damage. In response to mild oxidative stress the body can increase its antioxidant defense levels. Unfortunately, severe oxidative stress caused by toxins capable of making free radicals or depleting antioxidant defenses can lead to cell injury and death. There is increasing evidence that free-radical-induced oxidative stress contribute to diseases such as neurodegenerative disease, chronic inflammatory disease, cancer and cardiovascular disease. Alzheimer's disease is one neurodegenerative disease associated with the ageing brain. Recent evidence suggests the occurrence of oxidative damage in Alzheimer's disease brain and a central role for amyloid B-peptide. It has been shown that the amyloid B-peptide is heavily deposited in the brains of patients with Alzheimer's disease and in these regions of the brain, oxidative stress, particularly of neuronal lipids, has been found to be extensive. It has been postulated that myeloid B-peptide-induced oxidative stress leads to neurodegenertion in Alzheimer's disease brain and that myeloid $\beta$-peptide induces neuronal lipid peroxidation, protein oxidation and DNA oxidation by free radical mechanisms that can be inhibited by antioxidants.

\section{Oxidative stress in birds and mammals}

Comparisons between birds and mammals may reveal developmental patterns that have been conserved during evolution. For example, hepatic GPx and CAT specific activities increase in both birds and mammals during the final week before birth. Also, Wilson et al. (1992) found that, aside from hepatic GPx and CAT, however, the expression of antioxidant enzymes differ between chick and mammalian embryos in a number of ways. They have suggested that, the changes in SOD and GPx, which occur in chick brain during the final 2 weeks of embryonic development, may result from the particular timing of neuronal and glial proliferation and differentiation in this species. Although this explanation remains speculative, it is clearly evident that the developmental patterns of chick cerebral GPx and CAT differ from those of mammalian species. In the brain of the guinea pig embryo, for example, the activities of GPx and CAT increase during days 45-60 of gestation.

In the rat brain, on the other hand, the neonatal period from 19 days gestational age through 2 days after birth is marked by decreases in the specific activities of both enzymes. Contrastingly, in embryonic chick brain during the final 2 weeks, the specific activity of GPx doubles and that of CAT falls 4-folds. The ontogeny of SOD also varies between vertebrate species. $\mathrm{Cu}-\mathrm{Zn} \mathrm{SOD}$ is the predominant isozyme in late gestational and neonatal rat brain but MnSOD predominates in embryonic chick brain. Additionally, the specific activities of SOD enzymes in brain vary markedly during the development of embryonic chick, whereas they are maintained at constant level in guinea pig during days 45-60 of gestation and in rat from day 19 of gestation through 2 days after birth.

Mammalian life depends upon oxygen as the final acceptor of electrons in mitochondrial electron transport, but the process also generates toxic metabolites; reactive oxygen species (ROS) leak from mitochondria into the cytoplasm where they cause cellular damage by oxidizing a variety of biologically important molecules, including DNA, proteins, lipids, and carbohydrates. Lipid and protein peroxidation reactions play and imbalance of oxidants and antioxidants in favor of the former, and is capable of inflicting injury on membrane lipids, proteins and nucleic acids.

\section{Oxidative stress in aquatic organisms}

Despite the relative scarcity of information on the relationship between age and oxidative stress in aquatic organisms appear to consistent with the general definition of ageing as "the progressive accumulation of changes that are responsible for the decreased ability of organisms to maintain physiological homeostasis, which may eventually lead to functional impairment and even death". Furthermore, Dandpat et al. (2003) found that the antioxidant defenses play an important role in providing protection to the developing larvae from oxidative assault. As consequence of the reactivity of ROS and their potential to damage cells and tissues, marine and other organisms balance the production of these radicals with a wide variety of cellular antioxidant defenses. Prominent among these antioxidants are the enzymes super oxide dismutase (SOD), catalase (CAT) and glutathione peroxidase (GPx). Antioxidant enzymes can 
be induced by various environmental pro-oxidant conditions (i.e. increased ROS generation), e.g. exposure to various types of pollution, as well as being affected by other endogenous/exogenous factors, such as age and seasonably/reproductive cycle. In addition, there have been many studies on the endogenous antioxidant enzyme systems in fish particularly in relation to specific oxidative stresses.

\section{Bacterial oxidative stress}

Bacterial stress can be defined as a physiological perturbation, caused by environmental modifications (physical, chemical and/or nutritional) that can have many consequences for the bacteria, such as retarded growth and cell death (Farr and Kogoma, 1991; Fridovich, 1998; Duwat, 1999). Oxidative stress can cause several types of damage to the bacterial cell, including: i) metabolic pathway disruptions, ii) spontaneous mutations, and iii) bacteriostatic and bactericidal effects (Berlett and Stadtman, 1997; Fridovich, 1998). Oxygen by itself is unable to cause any damage to the cell; however, during the cellular processes (metabolic pathway), $\mathrm{O}_{2}$ is partially reduced to water, leading to the formation of reactive $\mathrm{O}_{2}$ species, which are the superoxide anion radical $\left(\mathrm{O}_{2}^{-}\right)$, the hydroxyl radical $\left(\mathrm{OH}^{-}\right)$, and hydrogen peroxide $\left(\mathrm{H}_{2} \mathrm{O}_{2}\right)$. These intermediates have a high oxidizing potential and thus are responsible for cellular oxygen toxicity (Farr and Kogoma, 1991; Fridovich, 1998; Storz and Imlay, 1999).

\section{The body's natural defense system}

A free radical, a destructive by-product of metabolism, looks to attach itself to cells, damaging or destroying them in the process. The body's cells, create potent natural antioxidant enzymes, Superoxide Dismutase (SOD), to attack the free radical and turns it into hydrogen peroxide. Hydrogen peroxide is dangerous also, so a second antioxidant enzyme, Catalase (CAT), steps in to break it down into harmless water and oxygen. SOD and CAT therefore have to work together and are considered the body's first line of defense against oxidative stress and aging.

\section{Oxidative defense system}

Production of oxyradicals or reactive oxygen species by cells is inevitable therefore cellular system has developed efficient defenses to neutralize the oxyradicals in course of evolution. The antioxidant defenses are highly conserved in nature. There are two major types of antioxidant defenses seen in organisms. The first type comprises of a cascade of enzymes known as antioxidant enzymes. These enzymes act in concert. The major enzymes belong to this category are superoxide dismutase, catalase, glutathione peroxidase and glutathione reductase. The other type constitutes of small antioxidant molecules, such as ascorbic acid, tocopherol, ubiquinone, uric acid and beta carotenoids. Each component of antioxidant defense system is discussed in brief.

\section{Enzymatic antioxidant defense system}

Super oxide dismutase is mainly distributed in cytoplasm and Mitochondria and cytoplasm of the cell. It dismutates superoxide radicals to hydrogen peroxide. Hydrogen peroxide is immediately neutralized by catalase and glutathione peroxidase. The catalase is peroxisomal in nature and neutralizes superoxide radicals into molecular oxygen and water. Glutathion peroxidase is distributed both in mitochondria and cytoplasm. It with the help of GSH and NADP reduces hydrogen peroxide to water. Glutathione reductase is present cytoplasm and helps in regeneration of GSH.

\section{Non-enzymatic defense system}

Among the major non-enzymatic antioxidants identified within the cell include reduced glutathione (GSHO, ascorbic acid (vitamin C), a-tocopherol (vitamin E), vitamin $\mathrm{A}$ and uric acid. The role played by these low molecular weight antioxidants in biological system are 1) Vitamin C- It is powerful reducing agent and is a major antioxidant. Scavanges superoxide, peroxide and hydroxyl radical; 2) Vitamin E- It is known as chainbreaking antioxidant as it functions to intercept lipid peroxyl radical. It also scavenges singlet oxygen and superoxide radical; 3) Vitamin A- Interrupts chain reaction of lipid peroxidation; 4) Glutathion (GSH)Scavanges hydoxyl radical, singlet oxygen, and superoxide radical; 5) Uric Acid- Powerful scavenger of singlet oxygen $\left(\mathrm{O}_{2}\right)$. Hydoxyl radical $\mathrm{OH}$ and superoxide radical, interrupts chain reaction of lipid peroxidation.

\section{Fish and reactive oxygen species}

Aerobic organisms generate reactive oxygen species (ROS) such as superoxide anion radical $\left(\mathrm{O}_{2}-\bullet\right)$, hydrogen peroxide $\left(\mathrm{H}_{2} \mathrm{O}_{2}\right)$ and hydroxyl radical $(\bullet \mathrm{OH})$ as a result of oxidative metabolism. $\cdot \mathrm{OH}$ can initiate lipid peroxidation (LPO) in tissues. To minimize the negative 
effects of ROS, fish, like other vertebrates, possess an antioxidant defence (AD) system, which utilizes enzymatic and non-enzymatic mechanisms. Some of the most important $\mathrm{AD}$ enzymes are superoxide dismutase (SOD), catalase (CAT), glutathione peroxidase (GPx) and glutathione reductase (GR), while the nonenzymatic defenses include Vitamins E, C and A, glutathione, carotenes and ubiquinol. When the activity of these antioxidant defence systems decreases or ROS production increases, oxidative stress may occur (Jos et al., 2005).

Mitochondria are the sites where reactive oxygen species are mainly produced, and red muscles are the most important source of mitochondria in endotherms. Therefore, this tissue is considered to be the main contributor to ROS generation in mammals and birds. However, in most fish red muscle makes up only a small proportion of tissues, and other tissues such as liver, kidney and also gills (as the first tissue in contact with the xenobiotics in the water) are more important in this regard (Jos et al., 2005). Oxidative stress biomarkers are becoming increasingly important in the field of ecotoxicology. The high number of pollutants can disturb the equilibrium between ROS and the $\mathrm{AD}$ system.It has been suggested that they could also be used in environmental monitoring programs. Various pesticides, pulp mill effluents and metals are some of the pollutants that have been reported to elicit oxidative stress in aquatic organisms but naturally occurring toxicants such as microcystins (MCs) are also capable of doing so. MCs are a family of cyclic peptide toxins produced by species of freshwater Cyanobacteria (blue-green algae), primarily Microcystis aeruginosa (Jos et al., 2005).

Jos et al. (2005) exposed fish to the cyanobacterial cells in two ways: mixed with a commercial fish food or crushed into a commercial fish food so that the toxins were released. Two different exposure times were studied: 14 and 21 days. The oxidative status of fish was evaluated by analyzing the level of lipid peroxidation (LPO), as well as the activities of antioxidant enzymes such as superoxide dismutase (SOD), catalase (CAT), glutathione peroxidase (GPx) and glutathione reductase (GR). The findings of the present investigation show that microcystins induce oxidative stress in a time-dependent manner and that the type of administration of the cyanobacterial cells influences the extent of these effects. Thus, the crushed cyanobacterial cells (released toxins) induced the antioxidant defences studied and increased the LPO level to a greater extent than the non-crushed cells. The liver was the most affected organ followed by kidney and gills.

\section{Fish mitochondria and ROS}

In fishes, irrespective of their thermoregulatory capacity or metabolic rate, the main physiological source of reactive oxygen species (ROS) is mitochondria. During active swimming, ROS is by and large provided by red muscle mitochondria. Other tissues such as lens, liver, heart, swim bladder, roe and blood also afford important ROS production and antioxidant levels in resting fish. A close relationship between structure and function is evident in fish mitochondrion with a surface-to-volume optimization by the size of cristae to maximize electron transfer. The mechanism of fish mitochondrial superoxide anion and ROS production as well as the mechanism of mitochondrial coupling and proton leak seems similar to that of mammals. Contrary to mammalian red cells, fish erythrocytes possess nuclei and mitochondria. The presence of cardiolipin and the absence of cholesterol in fish mitochondrial membranes confer a high structural flexibility. The difference in phospholipid unsaturation may explain the greater proton leak in endotherms compared to thermoconformers. Fish mitochondrial function changes on the adaptations to changes in temperature, $\mathrm{O} 2$ availability and $\mathrm{O} 2$ consumption related to changes in antioxidant status and ROS production (Filho, 2007). The information regarding the antioxidant defense system in fishes and their regulation are sporadic and scanty specially in Indian fishes. Indian water inhabits more than 200 species of fishes. The detail study of antioxidant defense system is required.

\section{Antioxidant defense system in fish}

Oxidative damage by free radicals in cell is caused due to an imbalance between the rate of production of oxidants and the rate of removal of these oxidants by antioxidants. Superoxide dismutase (SOD), catalase (CAT), glutathione peroxidase (GPx), glutathione reductase (GR), reduced glutathione (GSH), ascorbic acid (ASH), carotenoids and uric acid are cellular antioxidants, which protect the aerobic organisms from toxic effects of ROS. Although detail information on mammals is available but very little information is available on the antioxidant system of lower vertebrates particularly in fish. Fishes duel in aquatic environment where oxygen concentrations of fish is affected by various factors such as temperature, salinity, and season. Therefore, it will be interesting to study the antioxidant defense system in fish. 
Although much research work has been conducted in mammals regarding the antioxidant system, very little information is available on lower vertebrates particularly in fish. Fishes are poikilotherms, which dwell in aquatic environment where oxygen concentrations of water is affected by various factors such as temperature, salinity and season. Therefore, it will be interesting to study the antioxidant defense system in fish.

The aquatic environment is the sink for all sorts of pollutants. Fish, an aquatic animal can serve as a model biomarker of pollution. The impact of the antioxidant defense system is of great significance in case of aquatic animals, which exhibit seasonal metabolic variations, related to changes of environmental parameters such as temperature and to the physiological status of animals (Winston, 1991). A number of fishes reviewed here in, contain the major antioxidant enzymes i.e., SOD, CAT, and GPx depiction the ability to withstand against oxygen radicals. GSH and ASA activities have also been reported in some fishes. A synopsis of the published works on antioxidant system in both fresh water and marine fishes is given here under.

Baseline activities of SOD, CAT, and GPx in some tissues of common carp have been reported by Matkovics et al. (1977). In relation to vertebrates like frog, pigeon, rat, and pig, comparable tissue activities in carp were quite low for SOD, very high for peroxidase and intermediate between pigeon and mammals for catalase. Wdziecsak et al. (1982) measured the basal activities of SOD, peroxidase and CAT in erythrocytes from a no of fresh water and marine fish species. They consistently observed presence of high activities of peroxidase and low activities of CAT in erythrocytes. SOD activities were highly variable. Witas et al. (1984) investigated CAT and SOD levels in liver of five species of Antarctic fishes including three red blooded and two white blooded species. Catalase activities were very low in all the species. SOD activity was much lower in white blood fish in comparison to red blooded fish. The level of SOD activity in liver of fish was similar to those reported for birds and mammals.

Tappel et al. (1982) examined GPx activity in some tissues from five species of mammals and four species of fish. They found activities in fish to generally far below those of mammals except for carps whose GPx activity was similar to that of mammals. SOD has been subjected to detailed study in sword fish (Xiphias gladius) by Bannister et al. (1977). They determined the amino acid composition of hepatic cytosolic SOD $(\mathrm{Cu}-\mathrm{Zn})$. The sword fish enzyme displayed higher number of arginine and tyrosine residues in comparison to commercial bovine SOD. Aksnes and Njaa (1981) measured SOD, GPx and CAT activities in nine different fish species.

Radi et al. (1986) performed a comparative study on the activities of SOD, CAT and Gpx in the organ homogenates from three omnivorous fishes. They were barbell, crucian carp and common carp. Highest SOD activities were recorded in barbell, following crucian carp and common carp. Highest SOD activities were found in liver, followed by kidney, heart and spleen of all the species investigated. Perez-Campo et al. (1993) examined the SOD, CAT, GPx and GR activities in the trout. They found the activities of SOD, CAT, and GPx was more in liver than in brain while activity of GR was more in liver than in brain while activity of GR was higher in brain than liver. Activities of CAT, GPx and SOD were compared in retemirabilis and gas gland epithelium from swim bladder of six marine fishes by Morris and Albright (1984). Results of their study indicate direct relationship between oxygen concentration of tissue and SOD. No relation was established between oxygen concentration of tissue and CAT and GPx.

A study of detoxifying enzymes during the embryonic development in fish (Salmo iridaeus) was conducted by Aceto et al. (1994). A gradual increase of SOD, CAT, GT and GST activities was seen throughout embryonic development in all tissues of trout. GPx activity was found to be extremely low compared to CAT activity. SOD and GR activity was highest in liver. Distribution of Se-dependent GPx and Se-independent GPx forms in fish is specific. Heisinger and Dawson (1983) reported both forms of GPx in black bull head liver while in rainbow trout only Se-dependent form is present (Aceto et al., 1994).

Al-Ghais and Ali (1995) investigated the GST activity in gill of marine fishes from Arabian gulf. Highest GST activity was seen in gill cytosol of Scolopsis bunaculatus followed by Lethrimus mhsenoides and Lutjanus fulviflamma. Distribution of 3 no-enzymatic antioxidants namely ascorbic acid, Uric acid, reduced and oxidized GSH and their correlation with the tissue lipid peroxidation was investigated in liver and brain of trout by Lopez et al. (1993). Uric acid levels were low and oxidized glutathione levels were undetected in trout brain. Trout brain was also devoid of ascorbic acid. Results indicate that liver is well equipped with nonenzymatic antioxidants that brain tissue in fish. 
However, various other factors also affect antioxidant defense system in body as described below.

\section{Water oxygen concentration}

Antioxidant defense system of liver, brain and muscle of goldfish alters in response to anoxia, however, the magnitude of responses of different antioxidant defense system and oxidative stress varies from one tissue to other (Lushehak et al., 2001). Deep sea environment is a natural poor oxygenated environment. By comparing antioxidant defense enzymes in tissue of 16 species fish species dwelling in deep sea, it was observed that there was an adjustment of SOD and GPx activities in the fish (Janssens et al., 2000). The authors believes that the adjustment of the SOD and GPx activities to the decreased metabolic rate in deep-sea fishes are an adaptation of antioxidant defense against the production of reactive oxygen species during metabolism.

\section{Seasonal variations}

Seasonal variation in activities of SOD and peroxidase in erythrocytes of common carp, crucian and tench were investigated by Gabrylack et al. (1983). Higher enzyme activities were noted in spring than in autumn. Similar seasonal changes in SOD activity in erythrocytes of Abramis brama from 2 lakes of Poland were reported (Gabryelak and Tawfik, 1991) and diethyl dithiocarbamate on the form of SOD from cod liver (Gadus morhua). It was seen that the enzyme was thermostable between $30^{\circ} \mathrm{C}$ and $60^{\circ} \mathrm{C}$ and $70^{\circ} \mathrm{C}$ the enzyme rapidly deactivated than porcine SOD. However, at increased temperature exposure there is an increase of oxidative stress in gill and air sacs of male and female fish.

\section{Effects of diet}

Cowey et al. (1981) studied the effects of Mn deficient diet on $\mathrm{Mn}$ and $\mathrm{Cu}-\mathrm{Zn}$ SOD in tissues of rainbow trout. It was seen that Mn concentration was reduced in liver and heart tissues and also $\mathrm{Cu}$ and $\mathrm{Zn}$ concentration were reduced in liver. As a result activities of both MnSOD and $\mathrm{Cu}-\mathrm{Zn} \mathrm{SOD}$ in liver were reduced while only MnSOD activity was depressed in heart tissues. Heisinger and Dawson (1990) examined the effects of Se-deficient diets on GPx activities in black bullhead catfish tissues (liver and erythrocytes). A significant reduction in GPx activities in both the tissues during the 18-week treatment was observed Hidalgo et al. (2002) studied the effect of dietary Zn-deficiency and the metabolism of activated oxygen-species in rainbow trout and found that an oxidative stress appears as a consequence of $\mathrm{Zn}$ deficiency in this fish.

\section{Effect of hormones}

Varghese et al. (2001) studied the effect of thyroid hormones (T2 and T3) on lipid peroxidation and antioxidant enzyme activities in Anabas testudineus. They observed and increased lipid peroxidation and also increased activity of super oxide dismutase, glutathion peroxidase enzymes in hypothyroid fish treated with T2 (diiodothryonine) and T3 (triiodothryronine).

\section{Effects of pollutants}

Antioxidant enzymes in fish are known to respond to metals and chemicals present in aquatic system. Chaurasia et al. (1996) found that lead treatment in Clarias batrachus resulted in decrease of serum thyroid hormone concentration where as lipid peroxidation increased in a dose dependent manner. Lower doses of lead nitrate were lipid peroxidation increased in a dose dependent manner. Lower doses of lead nitrate were not effective with respect to thyroid function. Gabryelak and Klekot (1985) exposed common carp, crucian carp and tench to 10ppm paraquat for $9 \mathrm{hr}$ and measured activities or SOD, GPx, CAT as well as concentration of MDA. Significant increase in GPx activities of SOD, GPx, CAT as well as concentration of MDA Significant increase in GPx activities were observed at only two of four time points in common carp while MDA concentration was elevated in common and crucian carp at most time points.

Radi and Matkovies (1988) exposed common carp to either $\mathrm{CuSo} 4 \mathrm{ZnSO}_{4}$ for $24 \mathrm{hr}$ and measured SOD, GPx, CAT and MDA concentration in liver, gill and white muscle. High dose of copper enhanced GPx activity and MDA levels in most tissues while SOD and CAT activities tended to be depressed. Response to Zinc was highly variable. GPx activities increased in liver at high dose, but declined in gill and muscle at both dosages of Zn. CAT and SOD activities were generally inhibited although liver SOD was elevated at higher dose. Dautremepuits et al. (2002) studied the antioxidant response (catalase, glutathione s-transferase (GST) and Glutathione reductase activity) in liver of carp parasitized by Ptychobothrium spp. compared to healthy fish. In case of copper contamination of these fish the decrease in enzymatic activities observed was less pronounced in paracitized carp compared to healthy carp. 
Otto et al. (1996) observed that continuous exposure of rainbow trout to polychlorinated biphenyl (PBC) resulted in impaired inducibility of biochemical detoxification parameters and no adaptive response in rainbow trout. PCB induction of oxidative stress in fish was also confirmed by the work of Livingstone et al. (2000). Moreover, the authors clearly demonstrated that $\mathrm{NAD}(\mathrm{P}) \mathrm{H}$ dependent reactive oxygen species generation in mitochondrial and microsomal fractions of hepatic tissues of fish species of contaminated aquatic environment was higher than that of clean lakes. Using primary hepatocytes of European flounder (Platichthys flesus), Winzer et al. (2000) demonstrated an elevation in oxyradical formation by oxidative stressors such as hydrogen peroxide and benzo (a) pyrene. Pollutant such effluent of paper mill is found to induce oxidative stress in tissues of Heteropneustes fossilis (Fatima et al., 2000). Organophosphates also reported to induce oxidative stress in tissues of carp (Cyprinus carpio) and catfish (Ictalurus nebulosus) (Hai et al., 1995 and 1997). Oruc and Uner (2002) studied the effect of 2,4-D and azinphos methyl on antioxidant enzymes and lipid peroxidation the liver of Cyprinus carpio. Super oxide dismutase activity increased after azinphos methyl exposure to 48 and 96 hours. 2,4-D decreased the activity after the 48 hours and elevation was found between 72 and $96 \mathrm{hrs}$. Glutathione reductase, catalase activities and malondialdehyde levels remained constant in all the treatment groups compared with controls.

Herbicides are also reported to induce oxidative stress in fish organs. It has been proposed that herbicide molinate induces oxidative stress in hepatocyte and muscle tissues of European eel (Anguilla anguilla) by elevating GSG, GSH, GSSG, and GR levels (Pena-Llopis et al., 2001). But the same treatment caused severe depletion of muscular GSH level in the fish. The authors believe that elevated GSH in hepatic tissues of the species in response to the herbicide may be and adaptive response to the oxidative stress generated by the herbicide.

The study of a toxicant methyl mercury in a marine fish species led to undertake an investigation of metabolism of GSH in black sea bass (Braddon et al., 1985). It was seen that liver extracts contained all the GSH-dependent enzyme activities in a variety of fish species, it was presumed that GSH was indeed a necessary and active agent in cellular protection of fish. Rana et al. (1995) reported mercury induced lipid peroxidation in liver, brain and gills of fresh water fish, Channa punctatus. Longer exposure to mercury caused greater oxidative stress. GSH levels increase in the thiobarbituric acid reactive substance (TBA-RS) was recorded in brain, liver and muscle tissue of fresh water catfish Heteropneustes fossilis by exposure to $0.2 \mathrm{mg} / 1 \mathrm{HgCl}_{2}$ for 10,20 and 30 days (Bano and Hasan, 1989).

Cadmium exposure is also reported to affect the activities of SOD and CAT in erythrocytes of goldfish (Zikic et al., 1997 and 2001) observed that copper is more potent than cadmium in inducing oxidative stress in kidney of sea bass (Dicentrarchus labrax).

Surfactant of all category such as anionic, cationic and non ionic are reported to induce oxidative stress in hepatic, cardiac and renal tissues of tilapia (Oreochromis mossambicus) when the species was exposed to them at a sub lethal concentration of $1 \mathrm{ppm}$ (Bindu and Babu, 2001). However, the magnitude and pattern of oxidative stress found to be tissue specific and authors opined that the antioxidant defenses and the in vivo metabolism of the surfactants are the key factors in deciding the surfactant toxicity.

Pandey et al. (2001) studied the effect of single exposure of endosulphan (5ppb) on catalase glutathione peroxidase glutathione s-transferase and reduced glutathione of liver, kidney and gill of Channa punctatus (a freshwater fish). They observed a peroxidative damage in liver, kidney and gill in response to which levels of antioxidant were modulated. The reproductive and oxidative stress parameters measured in this study varied between seasons and mills suggesting responses to effluent are dynamic and effects are complicated by different receiving environments (Oakas et al., 2003).

Oxidative stress, i.e. pathological processes related to overproduction of reactive oxygen species (ROS) in tissues is one of important general toxicity mechanisms of many xenobiotics. Induction of oxidative stress after exposure to numerous xenobiotics was revealed experimentally as well under field conditions at both human and many species of other organisms including fish (Blaha et al., 2004). Oxidative stress was shown to be induced by anthropogenic contaminants as persistent organic pollutants (POPs), heavy metals, and also by toxins produced during massive blooms of Cyanobacteria (Blaha et al., 2004). Along with continuous worldwide anthropogenic water eutrophication, cyanotoxins (particularly peptide microcystins) are of growing environmental as well as health concern and were shown to cause serious adverse effects in human as well as aquatic organisms including fish (Blaha et al., 2004). 


\section{Conclusions}

The reactive oxygen species/ free radical generation is a continuous process in the biological system. Several types of antioxidative compounds are found in all organisms along with the all the fish species to protect their lipids against damage caused by reactive oxygen species. These compounds belong to various chemical groups and make use of their antioxidative effects via different modes of action. Fish contains various antioxidants for protection of their unsaturated lipids and other nutrients from reactive oxygen species. Oxidative protection of fish includes enzymatic, various watersoluble and lipid soluble antioxidant systems. The function of these antioxidants is to control pro-oxidants, scavenge free radicals and inactivate reactive oxygen species. Recently research on antioxidants has gained much interest due to increased evidence of the importance of antioxidants in human health. This interest has brought about considerable research on defining and finding components with anti-oxidative activity in humans and in biological systems.

Especially in fish there is a high risk of quality loss due to oxidation (Jeremiah, 2001; Medina et al., 2009). Lipid oxidation in meat and fish-products leads to rancid taste and off flavor and development of many different substances from which some have even adverse effects to human health (Ames et al., 1993). Oxidation limits storage time and thereby also affects marketing and distribution of both fish and meat products. Especially fish, being rich in n-3 polyunsaturated fatty acids (PUFA) is susceptible to peroxidation of PUFA resulting in restriction of storage and processing possibilities (Gray et al., 1996). Furthermore, peroxidative products, particularly aldehydes, can react with specific amino acids to form carbonyls (Uchida and Stadtman, 1993) and protein aggregates (Buttkus, 1966), causing additional nutritional losses. In red meat and also in red fish like salmon oxidation will not only deteriorate the lipids, but also the color (Faustman and Cassen, 1990).

Relatively few studies on the various antioxidants in fish are currently available. Studies on the interaction between the various endogenous antioxidants in fish are also very few. The relative concentration of antioxidants varies with the fish species as well as the type of fish muscle tissue. The quantity of these antioxidants may also fluctuate with storage time and handling post mortem. Control of lipid oxidation in fish involves utilizing processing and storage techniques that do not greatly decrease the activity of endogenous antioxidants.

\section{Conflict of interest statement}

Author declares that there is no conflict of interest.

\section{References}

Aceto, A., Amicarelli, F., Sacchatta, P., Dragani, B., Bucciarelli, T., Masciocco, L., Mirand, M., Ilio, C.D., 1994. Developmental aspects of detoxifying enzymes in fish (Salmo iridaeus). Free Rad. Res. 21, 285-294.

Aksnes, A., Njaa, L.R., 1981. Catalase, glutathione peroxidase and superoxide in different fish species. Comp. Biochem. Physiol. 69B, 893-896.

Al-Ghais, S.M., Ali, B., 1995. Xenobiotic metabolism by glutathione-s-transferase in gill of fish from Arabian Gulf. Bull. Environ. Contam. Toxicol. 55, 201-208.

Allen, R. G., 1991. Oxygen-reactive species and antioxidant responses during development: The metabolic paradox of cellular differentiation. Proc. Soc. Exp. Biol. Med. 196, 117-129.

Ames, B.N., Shigenaga, M.K., Hagen, T.M., 1993. Oxidants, antioxidants, and the degenerative diseases of aging. Proc. Nat. Acad. Sci. USA). 90(17), 7915-7922.

Bannister, J. V., Anastasi, A., Bannister, W. H., 1977. Cymosely super oxide dismutase from swordfish (Xiphias gladius L.) liver. Int. Biochem. 13, 1039-1042.

Bano, Y., Hasan, M., 1989. Mercury induced time dependent alterations in lipid profile and lipid peroxidation in different body organs of catfish, Heteropneuster fossilis. J. Environ. Sci. Hlth. 24B, 144-166.

Berlett, B.S., Stadtman, E.R., 1997. Protein oxidation in aging, disease and oxidative stress. J. Biol. Chem. 272, 2031320316.

Betteridge, D.J., 2000. What is oxidative stress? Metabol. 49(2), Suppl. 1, 2-8.

Bindu, P. C., Babu, P., 2001. Surfactant-induced lipid peroxidation in a tropical euryhaline teleost Oreochromis mossambicus (Tilapia) adapted to fresh water. Indian J. Exp. Biol. 39(11), 1118-22.

Blaha, L., Kopp R, Imkova K, Mare J. (2004). Oxidative Stress Biomarkers are Modulated in Silver Carp (Hypophthalmichthys molitrix Val.) Exposed to Microcystin-Producing Cyanobacterial Water Bloom Acta vet. brno, 73: 477-482

Braddon, S. A., Mcilvaine, C.M., Baltrop, J.E., 1985. Distribution of GSH and GSH cycle enzymes in black sea bass (Centropristis striata). Comp. Biochem. Physiol. 80B, 213-216.

Buttkus, H., Preparation and properties of trout myosin. J. Fish. Res. Board Canada. 23(4), 563-573.

Chaurasia, S.S., Gupta, P., Kar, A., Maiti, P.K., 1996. Lead induced thyroid dysfunction and lipid peroxidation in the fish Clarias batrachus with special reference to hepatic type 1,5-monoiodinase activity. Bull. Environ. Contam. Toxicol. 56, 649-654.

Dandapat, J., Chainy, G.B.N., Rao, K.J., 2003. Lipid peroxidation and antioxidant defense status during larval 
development and metamorphosis of giant prawn, Macrobrachium rosenbergii. Comp. Biochem. Physiol. Part C. 135, 221-233.

Dautremepuits, C., Betoulle, S., Vernet, G., 2002. Antioxidant response modulated by copper in healthy or parasitized carp (Cyprinus carpio L.) by Ptychobothrium spp. (Cestoda). Biochim. Biophys. Acta. 1573, 4-8.

Dhaunsi, G.S., Gulati, S., Singh, A.K., Orak, J.K., Asayama, K., Singh, I., 1992. Demonstration of $\mathrm{Cu}-\mathrm{Zn}$ superoxide dismutase in rat liver peroxisomes: Biochemical and immunochemical evidence. J. Biol. Chem. 267, 68706873.

Duwat, P., 1999. Stress response pathways in Lactococcus lactis. Recent Res. Devel. Microbiol. 3, 335-348.

Farr, S.B., Kogoma, T., 1991. Oxidative stress responses in $E$. coli and S. typhimurium. Microbiol. Rev. 55, 561-585.

Fatima, M., Ahmad, I.I., Athar, M., Raisuddin, S., 2000. Pollutant induced over activation of phagocytes is concomitantly associated with peroxidative damage in fish tissues. Aquatic Toxicol. 49, 243-250.

Faustman, C., Cassens, R.G., 1990. The biochemical basis for discoloration in fresh meat: A review. J. Muscle Food. 1, 217-243.

Fenton, H. J. H., 1894. Oxidation of tartaric acid in presence of iron. J. Chem. Soc. Trans. 65, 899-910.

Filho, D. W., 2007. Reactive oxygen species, antioxidants and fish mitochondria: Front Biosci. 12, 1229-1237.

Fridovich, I., 1998. Oxygen toxicity: A radical explanation. J. Exp. Biol. 201, 1203-1209.

Gabryelak, T., Klekot, J., 1985. The effect of paraquat on the peroxide metabolism enzymes in erythrocytes of freshwater fish species. Comp. Biochem. Physiol. 81C, 415-418.

Gabryelak, T., Piatkowska, M., Leyko, W., Peres, G., 1983. Seasonal variations in the activities or peroxide metabolism enzymes in erythrocytes of freshwater fish species. Comp. Biochem. Physiol. 75C, 383-385.

Gabryelak, T., Tawfek, N.S., 1991. Seasonal changes of superoxide dismutase activity in erythrocytes of Abramis brama from two different types of Poland lakes. Bull. Environ. Cantam. Toxicol. 47, 912-917.

Gray, J.I., Gomaa, E.A., Buckley, D.J., 1996. Oxidative quality and shelf life of meats. Meat Sci. 43(1), S111S123.

Hai, D.Q., Varga, I.S., Matkovics, B., 1995. Effect of an organophosphate on the antioxidant system of fish tissues. Acta Biol. Hung. 46(1), 39-50.

Hai, D.Q., Varga, S.L., Matcovics, B., 1997. Organophosphate effects on antioxidant system of carp (Cyprinus carpio) and catfish (Ictalurus nebulosus). Comp. Biochem. Physiol. Pharmacol. Toxicol. Endocrinol. 117C, 83-88.

Heisinger, J.F., Dawson, S.M., 1983. Effect of lelenium deficiency on liver and blood glutathione peroxidase activity in the black bullhead. J. Exp. Zool. 225, 325-328.

Hidalgo, M.C., Exposito, A., Palma, J.M., de la Higurera, M., 2002. Oxidative stress generated by dietary Zn-deficiency:
Studies in rainbow trout (Oncorhynchus mykiss). Int. J. Biochem. Cell Biol. 34, 183-193.

Janssens, B.J., Childress, J.J., Baguet, F., Rees, J.F., 2000. Reduced enzymatic antioxidative defense in deep-sea fish. J. Exp. Biol. 203, 3717-3725.

Jeremiah, L.E., 2001. Packaging alternatives to deliver fresh meats using short- or longterm distribution. Food Res. Internat. 34(9), 749-772.

Jos, A., Pichardo, S., Prieto Ana, I., Repetto, G., Vazquez Carmen, M., Moreno, I., Camean Ana, M., 2005. Toxic cyanobacterial cells containing microcystins induce oxidative stress in exposed tilapia fish (Oreochromis sp.) under laboratory conditions. Aquatic Toxicol. 72, 261-271.

Knight, J.A., 1995. Diseases related to oxygen-derived free radicals. Ann. Clin. Lab. Sci. 25, 111-121.

Livingstone, D.R., Mitchelmore, C.L., O’Hara, S.C., Lemaire, P., Sturve, J., Forlin, L., 2000. Increased potential for NAD (P) H-dependent reactive oxygen species production of hepatic sub cellular fractions of fish species with in vivo exposure to contaminants. Mar. Environ. Res. 50, $57-$ 60.

Lushchak, V.I., Lushchak, L.P., Mota, A.A., Hermes-Lima, M., 2001. Oxidative stress and antioxidant defenses in goldfish Carassius auratus during anoxia and reoxygenation. Am. J. Physiol. Regul. Integr. Comp. Physiol. 280(1), 100-107.

Matkovics, B., Novak, R., Hahn, H.D., Szabo, L., Varga, S.Z.I., Zalesnna, G., 1977. A comparative study of some more important experimental animal peroxide metabolism enzymes. Comp. Biochem. Physiol. 56b, 31-34.

Medina, I., Gallardo, J.M., Aubourg, S.P., 2009. Quality preservation in chilled and frozen fish products by employment of slurry ice and natural antioxidants. Int. J. Food Sci. Technol. 44(8), 1467-1479.

Meyer, M., Schreck, R., Müller, J. M., Baeuerle, P. A., 1994. Oxidative Stress, Cell Activation and Viral Infection Part of the series Molecular and Cell Biology Updates. pp.217235.

Morris, S.M., Albright, J.T., 1984. Catalase, glutathione peroxidase and super oxide dismutase in retermiralile and gas gland epithelium of six species of marine fishes. J. Exp. Zool. 232, 29-39.

Oakes Ken, D., McMaster Mark, E., Pryce Andrea, C., Munkittrick Kelly, R., Portt Cam, B., Hewitt, L. M., MacLean Dan, D., Kraak Glen, J. Van Der, 2003 Oxidative stress and bioindicators of reproductive function in pulp and paper mill effluent exposed white sucker. Toxicol. Sci. 74, 51-65.

Oruç, E.O., Uner, N., 2000. Combined effects of 2,4-D and azinphosmethyl on antioxidant enzymes and lipid peroxidation in liver of Oreochromis niloticus. Comp. Biochem. Physiol. C. Toxicol. Pharmacol. 127(3), 291296.

Otto, D.M.E., Moon, T.W., 1996. Endogenous antioxidants systems of two teleost fish, the rainbow trout and the black bull head, and the effect of age. Fish Physiol. Biochem. 15, 349-358. 
Pandey, S., Ahmad, I., Parvez, S., Bin-Hafeez, B., Haque, R., Raisuddin, S., 2001. Effect of endosulfan on antioxidants of fresh water fish Channa punctatus Bloch. 1. Protection against lipid peroxidation in liver by copper pre-exposure. Arch. Environ. Contam. Toxicol. 41, 345-352.

Pena-Llopis, S., Pena, J.B., Sancho, E., Fernandez-Vega, C., Ferrando, M.D., 2001. Glutathione-dependent resistance of the European eel, Anguilla anguilla to the herbicide molinate. Chemosphere. 45, 671-681.

Perez-Campo, R., Lopez-Torres, M., Rojas, C., Cadenas, S., Barja, G., 1993. A comparative study of free radicals in vertebrates. Antioxidant enzymes. Comp. Biochem. Physiol. 105B, 749-755.

Pradeep, K.G., Seerwani, N., Laloraya, M., Nivsarkar, M., Verma, S., Singh, A., 1990. Superoxide dismutase as a regulatory switch in mammalian testicular steroidogenesis. Biochem. Biophys. Res. Commun. 173(1), 302-308.

Radi, A.A.R, Hai, D.Q., Matkovics, B., Gabryelak, T., 1985. Comparative antioxidant enzyme study in fresh water fish with different types of feeding behavior. Comp. Biochem. Physiol. 81C, 395-399.

Rana, S.V.S., Singh, R., Verma, S., 1995. Mercury-induced lipid peroxidation in the liver, kidney, brain and gills of freshwater, Channa punctatus. Jpn. J.Icthyol. 42, 255-259.

Shaw, S., Jayatilleke, E., 1990. Ethanol-induced iron mobilization: Role of acetaldehyde oxidase generated superoxide. Free Rad. Biol. Med. 9, 11-17.

Shivakumar, B.R., Anandateerthavarada, H.K., Ravindanath, V., 1991. Free radical scavenging systems in developing rat brain. Int. J. Dev. Neurosci. 9(2), 181-185.

Sinclair, A. J., Barnett, A. H., Lunec, J., 1991. Free radicals and antioxidant systems in health and diseases. J. Appl. Med. 17, 409-415.

Stat, D. A., 1988. Effects of tocopherol depletion on the regional differences in adrenal microsomal lipid peroxidation and steroid metabolism. Endocrinol. 123, 975-980.

Storz, G., Imlay, J.A., 1999. Oxidative stress. Curr. Opin. Microbiol. 2, 188-194.

Tandon, V., Gupta, M. D., Tandon, R., 2005. Free radicals/ reactive oxygen species. JK-Practitioner. 12(3), 143-148

Tappel, M.E., Chaudiere, J., Tappel, A.L., 1982. Glutathione peroxidase activities of animal tissues. Comp. Biochem. Physiol. 73B, 945-949.

Turrens, J. F., Alexandre, A., Lehninger, A. L., 1985. Ubisemiquinone is the electrone donor for super oxide formation by complex III of heart mitochondria. Archv. Biochem. Biophys. 237, 408-414.

Uchida, K., Stadtman, E.R., 1993. Covalent attachment of 4 hydroxynonenal to glyceraldehyde-3-phosphate dehydrogenase - A possible involvement of intramolecular and intermolecular cross-linking reaction. J. Biol. Chem. 268(9), 6388-6393.

Varghese, S., Shameena, B., Oommen, O.V., 2001. Thyroid hormones regulate lipid peroxidation and antioxidant enzyme activities in Anabas testudineus (Bloch). Comp. Biochem. Physiol. B: Biochem. Mol. Biol. 128, 165-171.

Wdziecsak, J.G., Zalesna, G., Bartkowiak, A., Witas, J., Leydo, W., 1981. Comparative studies on superoxide dismutase, catalase and peroxidase levels in erythrocytes of different fish species. Comp. Biochem. Physiol. B: 68, 357-358.

Wilson, J.X., Lui, E.M.K., DEL Maestro, R.F., 1992. Developmental profiles of antioxidant enzymes and trace metals in chick embryo. Mech. Ageing Dev. 65, 51-64.

Winston, G.W., 1991. Oxidants and antioxidants in aquatic animals. Comp. Biochem. Physiol. 100c, 173-176.

Winzer, K., Becker, W., van Noorden, C.J.F., Kohler, A., 2000. Short time induction of oxidative stress in hepatocytes of the European flounder (Platichthys flesus) Mar. Environ. Res. 50, 495-501.

Witas, H., Gabryelak, T., Matkovics, B., 1984. Comparative studies on superoxide dismutase and catalase activities in livers of fish and other Antarctic verebrates. Comp. Biochem. Physiol. 77, 409-411.

Zikic, V., Stajn, A.S., Ognjanovic, B.I., Pavlovic, B.I., Saicic, Z.S., 1997. Activities of super oxide dismutase and catalase in erythrocytes and transaminases in the plasma of carps (Cyprinus carpio L.) exposed to cadmium. Physiol. Res. 46, 391-396.

Zikic, V., Stajn, A.S., Ognjanovic, B.I., Pavlovic, B.I., Saicic, Z.S., 2001. Activities of super oxide dismutase and catalase in erythrocytes and plasma transaminases of goldfish (Carassius auratus gibelio Blooch) exposed to cadmium. Physiol. Res. 50, 105-111.

\section{How to cite this article:}

Tripathy, A., 2016. Oxidative stress, reactive oxygen species (ROS) and antioxidative defense system, with special reference to fish. Int. J. Curr. Res. Biosci. Plant Biol. 3(10), 79-89.

doi: http://dx.doi.org/10.20546/ijcrbp.2016.310.010 